\title{
Cambio social y reserva de ley*
}

\section{DR. DIETER LORENZ, UNIVERSIDAD DE KONSTANZ}

\section{LA PROBLEMÁTICA}

El tema acerca de la relación entre la reserva de ley y el cambio social se encuentra en el punto de intersección entre la protección de los derechos fundamentales y la división de poderes, por una parte, y entre las competencias legislativa y judicial, por otra. El interés sobre dicho tema emana de una perceptible tendencia de la jurisprudencia de exigir en el enjuiciamiento de nuevos desarrollos una reglamentación legal justamente hecha para ellos y, cuando tal reglamentación no exista, de declarar la actuación estatal basada en el derecho presente como ilícita.

Una nueva aparición de tales características se da, por ejemplo, en el funcionamiento de un laserdromo. En él, los jugadores se disparan mutuamente con aparatos de laser semejantes a pistolas y, de esta manera, simulan el asesinato de seres humanos. Una actividad de tales características supone, según la jurisprudencia dominante, una infracción contra la dignidad humana y, por ello, puede ser prohibida por la policía dado que ésta está autorizada mediante una cláusula legal general a intervenir con vistas a la protección del orden público (cf. con más detalles Gröpl/Brandt, Verwaltungsarchiv 95, 2004, pp. 223, 246 ss.). Sin embargo, el Consejo de Estado no consideró suficiente esta autorización para el Estado. A la vista de la expansión de laserdromos en Alemania y en Europa, el Consejo de Estado requirió por principio una base legal especial para que tal prohibición y con ésta la intromisión en la libertad de profesión se llevara a cabo. No obstante, el Consejo concedió al legislador - que ya se había enfrentado en varias ocasiones ante el problema - un período transitorio para la observación del desarrollo siguiente (decisiones del Consejo de Estado, tomo 115, p. 189).

\footnotetext{
* Ponencia ante la Facultad de Derecho de la Universidad Santo Tomás, de Bogotá, pronunciada el 16 de marzo de 2004.
} 
En cambio, también fue declarado nulo un decreto sobre perros de pelea apoyado en la cláusula general policial (decisiones del Consejo de Estado, tomo 116, p. 347). Al parecer, la cláusula general sólo permitiría una intervención en caso de peligros concretos, es decir, el peligro emanado de un perro concreto. Por el contrario, sería necesaria una situación legal especial para llevar a cabo medidas de protección general sobre perros de pelea.

El trasfondo de estos ejemplos fue la aparición de nuevos fenómenos sociales -laserdromos, peligros creados por perros de pelea -, para los que no consideró adecuadas las reglamentaciones generales existentes debido a un cambio social.

¿Qué relevancia tiene entonces el cambio social en el Derecho? Para contestar esta pregunta debemos tener en cuenta dos aspectos.

\section{LA RELEVANCIA DE LA FALTA DE APLICA- CIÓN JUDICIAL DE LAS LEYES}

\section{La tarea de reglamentación legal}

La vinculación entre Derecho y cambio social es evidente. Si se entiende el Derecho como el orden externo obligatorio para el comportamiento humano, entonces las normas jurídicas deben orientarse a las condiciones sociales concretas para cumplir con su función dirigente. Esto significa que el Ordenamiento Jurídico vigente debe reaccionar inevitablemente ante cambios en las circunstancias reales de vida. Esto tiene validez tanto para innovaciones tecnológicas como para cambios sociales en sentido estricto.
La invención e inserción del ferrocarril, de camiones y de aviones, requirió regulaciones jurídicas; la creación de leyes sociales y de sistemas de aseguración social fue la respuesta normativa a los profundos cambios surgidos de la Revolución Industrial en la Europa del siglo XIX. En la época actual tienen una relevancia similar la utilización de la energía atómica, la ingeniería genética, el manejo de los nuevos medios de comunicación (apuntes: telecomunicación y firma electrónica) o la necesidad de una armonización de los sistemas sociales en los seguros de pensiones y de enfermedad.

Sin embargo, es precisamente en este último ámbito donde se muestra de forma clara que la necesidad de legislación es diferente en cada país y que incluso dentro de un mismo Estado puede ser enjuiciado de manera distinta. La pregunta sobre la necesidad de una reglamentación legal como respuesta a nuevos desafíos reales es por eso en primer lugar de naturaleza teórico-estatal o jurídico-política. La cuestión obtiene calidad jurídica en tanto y en cuanto la Constitución en determinados casos explícitamente prevea la necesidad de una reglamentación legal. Este tipo de mandatos legislativos son poco frecuentes en la Constitución; en la Ley Fundamental existen por ejemplo con respecto a la protección de la maternidad (artículo 6, apartado $4^{\circ}$ ) o a la prohibición de guerra de agresión (artículo 26, apartado $1^{\circ}$ ).

En cambio, a menudo se encuentran reservas de ley. La reserva de la ley exige, generalmente hablando, "que la actuación estatal en determinados ámbitos fundamentales sea legitimada mediante una ley formal" (decisiones de la Corte Constitucional, Tomo 98, pp. 218, 251). Así, por ejemplo, según el artículo 106, apartado $3^{\circ}$ Ley Fundamental, la atribución del impuesto sobre la venta entre el Estado Federal y los estados federados sólo puede ser reglamentada a través de una ley federal (por consiguiente no 
mediante un acuerdo); sólo a través de una ley pueden ser creadas autoridades federales (artículo 87, apartado $3^{\circ}$ Ley Fundamental). Y corresponde a la tradición de los estados democráticos, que la fijación del presupuesto general del Estado requiera una ley parlamentaria (artículo 110, apartado $2^{\circ}$ Ley Fundamental; artículo 349 de la Constitución de Colombia).

\section{LA RESERVA DE LEY RESULTANTE DE LOS DERECHOS FUNDAMENTALES}

La forma de aparición más importante es la reserva de ley resultante de los derechos fundamentales, a la cual se limitan las explicaciones que siguen.

La reserva de ley en este ámbito es en primera línea una reserva de intromisión: la actuación estatal, que se refiere al particular y se entromete en su posición jurídica, en "libertad y propiedad", requiere una autorización legal (cf. Hesse, Grundzüge des Verfassungsrechts der Bundesrepublik Deutschland, $19^{\circ}$ ed. 1993, notas 201, 509). De forma más general y más allá de esta manifestación clásica de la reserva de ley, puede ser también constitucionalmente prevista la elaboración legal de determinados ámbitos relacionados con los derechos fundamentales. El alcance de la vinculación resultante, depende de la llamada teoría sobre la esencialidad: el legislador tiene que promulgar por sí mismo todas las reglamentaciones que son esenciales para la protección y realización de los derechos fundamentales (cf. decisiones de la Corte Constitucional, tomo 49 pp. 89,126 ss.; tomo 98 pp. 218, 251; tomo 101 pp. 1, 34).

Así, el ente radiodifusivo - especialmente en su manifestación dual con establecimientos jurídico-públicos y suministradores privados - sólo puede cumplir con el mandato constitucional de la libre formación de la opinión pública (artículo 5, apartado $1^{\circ}$, frase 2 Ley Fundamental) a base de una elaboración legal (decisiones de la Corte Constitucional, tomo 12 pp. 205, 262; tomo 73 pp. 118, 153). Estructuralmente comparable con lo anterior, son determinadas actividades como el funcionamiento de instalaciones nucleares o laboratorios de ingeniería genética que conllevan peligros elementales para la sociedad y que sólo son permitidos cuando la ley en principio los admite. Esta monopolización legislativa de un ámbito de la vida significa para el particular, no obstante, una limitación de sus derechos fundamentales. Dado que el particular no puede actuar si no existe una reglamentación legal, se encuentra privado - en este ámbito - de su libertad de actuación y decisión. En 1989, con anterioridad a la promulgación de la Ley de ingeniería genética de 1991, se vio como (jurídicamente) ilícita una instalación de ingeniería genética y su autorización fue denegada (decisión del Tribunal administrativo-contencioso de Hessen, Neue Zeitschrift für Verwaltungsrecht 1990, p. 276; crítico p.ej. Sendler, Op. Cit., p. 231). Como resultado, en un caso de tales características, la reserva de ley no se refiere a la actuación estatal, sino a la del particular; aunque determinada a proteger los derechos fundamentales, la reserva de ley se dirige contra el titular de los derechos fundamentales. Esto significa en realidad que ciertas actuaciones de particulares no sean protegidas por el derecho principal a la libertad según el art. 2, párrafo 1 Ley Fundamental. Esta consecuencia es estraña y exigiría una investigación adicional, que empero no puede darse en el contexto.

\section{RESERVA DE LEY Y CONTROL DE LAS NORMAS}

a) La observancia de la reserva de ley, como principio constitucional que es, sucumbe necesariamente al control judicial. El punto de control inmediato es el acto estatal respectivo que está sometido a la reserva de 
ley como, por ejemplo, la interdicción policial de una actividad concreta o la promulgación de un decreto-ley que prohibe los perros de pelea. Sin embargo, el Tribunal no sólo comprueba si el acto está legitimado por la base legal presente, sino también si la base cumple por sí misma con Ios requisitos constitucionales de la reserva de ley; si, por ejemplo, está suficientemente determinada. Si este control indirecto de la ley alcanza un resultado negativo, entonces tiene efectos de hecho como un mandato judicial de legislar. Esto se debe a que la vulneración de los preceptos constitucionales por la ley se sanciona a través de la sentencia sobre el acto ejecutivo que sin base legal resulta ilegal y hay que revocarlo. El legislador que quiere cumplir con su tarea de ordenar jurídicamente las condiciones sociales se enfrenta a la necesidad de elaborar las correspondientes bases legales para la actuación del Ejecutivo. El legislador tiene que orientarse, respecto al contenido, a las pautas de la jurisprudencia y, en última instancia, a las pautas de la Corte Constitucional.

b) La constelación esbozada anteriormente es una consecuencia necesaria de la sumisión de la legislación a la Constitución, prevista en el artículo 20, párrafo 3; y artículo 1, párrafo 3 Ley fundamental, y de la apertura de un control judicial normativo. Dicho control no solo es posible de forma inmediata ("principal") a través de la Corte Constitucional, sino que también lo es de forma mediata ("incidental") a través de los tribunales. Así, la jurisprudencia recibe una considerable influencia sobre la legislación. No obstante, la competencia para desestimar una ley promulgada bajo la vigencia de la Ley Fundamenal se ve monopolizada en el seno de la Corte Constitucional. Cuando un tribu- nal ordinario estime una tal ley como inconstitucional tiene que presentar esta cuestión ante la Corte Constitucional.

El motivo de un -principal o incidental- control normativo tal, puede ser la violación de preceptos constitucionales en la promulgación de una ley, por ejemplo, una ley tributaria que confíe a las autoridades tributarias el establecimiento de tasas de impuestos y sea por ello demasiado indeterminada. La inconstitucionalidad también puede derivarse de nuevos conocimientos jurídico-constitucionales, cuando a raíz de ellos sean deducidos contenidos más amplios del derecho fundamental afectado como, por ejemplo, la libertad de profesión. Lo mismo puede suceder cuando el ámbito de aplicación de una reserva de ley haya sido ampliado. Este es, por ejemplo, el caso en las relaciones administrativas especiales tales como las relaciones escolares. Anteriormente fueron vistas como parte interna de la Administración, en las que ni los derechos fundamentales ni la reserva de ley tenían validez, hasta que se reconocía que los escolares afectados y sus padres eran titulares de derechos fundamentales en los que sólo se puede intervenir a base de una ley (decisiones de la Corte Constitucional, tomo 34 pp. 165, 192; tomo 47 pp. 46, 80; Maurer, Allgemeines Verwaltungsrecht, $14^{\circ}$ ed. 2002, § 6 nota 20).

\section{La relevancia jurídica del cambio social}

\section{La posición del legislador}

Una situación básicamente distinta existe cuando la ley no se presenta como inconstitucional desde el principio o tras el nuevo enjuiciamiento de un supuesto inalterado, sino cuando la sentencia de inconstitucionalidad se basa en el 
cambio social, el cual se entiende como una variación de las condiciones sociales reales cuya dirección corresponde al Derecho. También aquí es tarea primaria del legislador considerar tales cambios a través de ajustes, así como a través del desarrollo de las normas actuales; en consonancia con ello, la mayor parte de la legislación consiste en la modificación de leyes ya existentes teniendo en cuenta las condiciones actuales de un ordenamiento jurídico real con alta densidad normativa.

De este modo, partiendo de preceptos generales, se han desarrollado muchas reglamentaciones especiales en ámbitos de derecho particulares, según las necesidadades jurídica y social. Este procedimiento se muestra de manera más urgente en el derecho penal, donde la máxima constitucional estricta "nulla poena sine lege" permite el castigo de injusticias susceptibles de penalización sólo sobre una base legal explícita. Un ejemplo histórico que data del año 1900 es la evacuación no autorizada de energía eléctrica, que por falta de existencia de una cosa en sentido jurídico no supone hurto y por ello sólo tras la creación de un hecho delictivo especial pudo ser castigado (decisiones del Tribunal supremo del Reich, sala de lo penal, tomo $29 \mathrm{p}$. 111; tomo 32 p. 165. Cf. parágrafo 248c del código penal). Ejemplos modernos son las variadas $y$ detalladas situaciones de hecho de la criminalidad referida a autómatas y a ordenadores, que no quedan incluidas en los delitos tradicionales del fraude o de la apropiación indebida.

También en el derecho ambiental y en el derecho económico (tema de nuestro seminario) se encuentran numerosos casos al respecto. El derecho de residuos y el derecho de protección contra inmisiones sirven en gran parte para defender contra peligros y por eso tienen sus raíces en el derecho policial general. Se excluyó de la reglamentación general de la actividad industrial (ley de la industria - Gewerbeordnung) la reglamentación especial de la artesanía, a través de la ley reguladora de la artesanía (Handwerksordnung). Así mismo, muchas reglamentaciones de autorización y control, con respecto a empresas industriales y con la meta de la protección del público, tienen sus orígenes en la finalidad general del derecho policial, a saber, de la defensa contra peligros. Ellas han sido diferenciadas cada vez más con respecto a actividades singulares particulares como, por ejemplo, centros hospitalarios privados (parágrafo 30 Ley de la industria), actos de baile (parágrafo 33b Ley de la industria), o la empresa de subasta (parágrafo $34 \mathrm{~b}$ Ley de la industria), las cuales son formas de aparición especial de la actividad industrial.

\section{LA INJERENCIA DE LA JURISDICCIÓN}

El legislador intenta en muchas ocasiones tener en cuenta la alta dinámica de la vida social moderna mediante reglamentaciones elásticas que son susceptibles de recibir también nuevos desarrollos. El prototipo de esta flexibilidad es la cláusula general, por ejemplo, en el derecho policial. La policía tiene que tomar las medidas necesarias para defender la seguridad pública o el orden público contra peligros. Cuando se trata de reglamentaciones en el ámbito de aplicación de la reserva de ley - y este es precisamente el caso de intromisiones policiales - pueden surgir fácilmente dudas acerca de si ellas bastan al principio de precisión.

Pero también en los casos en que no haya una intromisión inmediata, una norma de autorización puede hacer surgir dudas, de igual modo que una norma de intromisión inmediata. Este es especialmente el caso cuando las condiciones que persigue regular una reglamentación han cambiado profundamente. Para casos extremos de este tipo la jurisprudencia de la Corte Constitucional ha decidido que una ley puede resultar, como consecuencia del desarrollo real, 
inconstitucional cuando se muestre una violación evidente del principio de igualdad. Una violación de este tipo se vio en que la prohibición legal de proporcionar descuentos en la venta para proteger a la economía de la clase media sólo era válida para los grandes almacenes, mientras que los supermercados y las demás grandes superficies comerciales surgidos con posterioridad no se encontraron en el ámbito de aplicación de la ley aunque su situación era comparable con la de los grandes almacenes (decisiones de la Corte Constitucional, tomo 21, p. 292).

Los cambios aquí investigados tienen una naturaleza básicamente distinta. No provocan contradicciones inmediatas respecto a la Constitución, sino que dentro del punto de vista del juez competente sólo parecen insuficientes para ciertas aplicaciones. Respecto a la estructura y la metodología, la situación es comparable con la primacía de aplicación del Derecho Comunitario Europeo. También en esta constelación el derecho nacional, en colisión con el derecho comunitario, no puede ser aplicado sobre ciertos supuestos con relevancia europea, aunque no pierde su validez (cf. Streinz, Europarecht, 3. ed. 1996, nota 200). De modo semejante, según el entendimiento de la jurisprudencia, desarrollos sociales o diversificaciones hacen surgir un déficit de reglamentación. Se plantea con todo el rigor la cuestión de quién -legislador o jueztiene la competencia, primero de declarar un déficit, segundo de decidir si el déficit tiene que ser equilibrado, y tercero cuál debe ser el contenido de la posible reglamentación suplementaria.

\section{LA SENTENCIA SOBRE EL "PAÑUELO DE CABEZA" DE LA CORTE CONSTITUCIONAL}

Dicha jurisprudencia exige la competencia para las dos primeras cuestiones. Esto se demuestra claramente pero a la vez autoritariamente en la llamada sentencia del "pañuelo de cabeza" de la Corte Constitucional del 24 de septiembre de 2003 (Neue Juristische Wochenschrift 2003 p. $3111)$.

La administración escolar desestimó la contratación de una maestra que, como creyente musulmana, intentó llevar en la escuela y en la clase sin excepción un pañuelo de cabeza. La base legal de la desestimación fue la reglamentación contenida en el artículo 33, apartado $2^{\circ}$ de la Ley Fundamental y en la Ley de los funcionarios, según las cuales el acceso a cargos públicos, por tanto también al cargo de maestra, exige la idoneidad para ello. Sin embargo, la idoneidad falta cuando hay que suponer que el futuro maestro, como representante del Estado, no vaya a cumplir con su deber oficial de mantener la neutralidad estricta en asuntos de ideología y religión dentro de la clase. Una vulneración de los deberes oficiales es especialmente la influencia religiosa sobre los alumnos, que también puede realizarse mediante un vestido típico de la religión o el llevar ostensiblemente símbolos religiosos. Según el parecer de la Administración y de los tribunales de lo contencioso-administrativo este fue el caso del pañuelo de cabeza islámico (decisiones del Consejo del Estado, tomo 116 p. 359).

Contrario a esto, la Corte Constitucional decidió en el recurso de amparo de la maestra que ella es vulnerada en su derecho fundamental de la libertad religiosa. Esta estimación podría ser corroborada según el punto de vista de que a la afectada le ha sido rechazado el libre ejercicio de su culto aunque sea en la escuela. En cambio, es sorprendente la motivación de la Corte Constitucional de que para la intromisión en el derecho fundamental no existe una base legal suficientemente precisa, pues la Administración había basado su decisión en normas jurídicas que hasta ahora no habían sido dudadas respecto a su capacidad para justificar tal decisión prohibitiva. Por eso, esta sentencia ha sido muy critica- 
$\mathrm{da}$, ante todo por el voto minoritario de los tres magistrados disentidores (Neue Juristische Wochenschrift 2003, p. 3117).

Para nuestro contexto es interesante que al parecer las bases jurídicas existentes ya no son suficientes porque entretanto han cambiado las circunstancias relevantes. "El cambio social conectado con la cada vez mayor pluralidad religiosa" - así la Corte Constitucional - "puede ser causa de una nueva determinación del alcance admisible de referencias religiosas en la escuela". Y a continuación: "No obstante el legislador competente del estado federado tiene la libertad de crear la base legal hasta ahora inexistente". En realidad, por supuesto sí existe una base legal, sólo sucede que aparentemente la Corte Constitucional no está de acuerdo con el status $q u o$ religioso en la escuela. Apoyada por la casación de la decisión administrativa formalmente legal, la Corte recomienda al legislador transferir al ámbito escolar el estado social logrado según su punto de vista o adoptar nuevamente una reglamentación legal para confirmar la situación jurídica vigente.

Pero, en efecto, el parlamento competente se había negado expresamente con unanimidad a regular en una ley la prohibición del pañuelo de la cabeza en la escuela. Estimaron la situación legal suficientemente estable para la negativa de una colocación, porque el llevar el pañuelo se presentó como violación de la obligación a la neutralidad del funcionario y por eso causó un deficit de idoneidad. De hecho, incitado por el voto de la Corte Constitucional siete de los dieciseis estados federados competentes para la legislación escolar han comenzado entretanto un trámite para excluir legalmente el pañuelo de cabeza de la enseñanza escolar. No es visible cuál es la ganancia para el Estado de Derecho en este incremento artificial de la existencia normativa.

\section{EVALUACIÓN CONSTITUCIONAL}

Bajo una mirada justa, esta presión judicial indirecta al legislador representa una vulneración del principio del Estado de Derecho sobre la separación de poderes (artículo 20, apartados $2^{\circ}, 3^{\circ}$ Ley Fundamental). La jurisprudencia, especialmente clara en la sentencia de la Corte Constitucional previamente mencionada, se remite a la reserva de ley, pero a causa de ésto infringe al mismo tiempo este principio constitucional. ¿Cómo se puede explicar esta contradicción?

\section{La reserva de ley y la reserva parla- mentaria}

La reserva de ley tiene dos orígenes. Bajo aspectos del Estado de Derecho sirve a la protección del ciudadano en sus derechos. Intromisiones en la libertad y en la propiedad tienen que ser admitidas por una ley parlamentaria formal. El legislador tiene la responsabilidad para delimitar por sí mismo la esfera de los derechos fundamentales de sus ciudadanos. Dado que las leyes sólo pueden ser promulgadas por el Parlamento, esta responsabilidad fundamenta también una reserva para la decisión parlamentaria. Ésta se basa, no obstante, sobre todo, en la legitimación democrática especial del parlamento, directamente elegido por el pueblo, y por eso no exige necesariamente la forma de ley. Sin embargo, cuando se trata de reglamentar los derechos fundamentales, la reserva de ley derivada del principio del Estado de Derecho y la reserva parlamentaria fundada en la democracia son congruentes. De esta manera, la reserva de ley suplanta totalmente las instancias decisorias no parlamentarias y tiene efectos no sólo frente al poder ejecutivo, sino también frente al poder judicial. En general, así como en el ámbito de la reserva de ley, los tribunales no pueden asumir el puesto del legislador (decisiones de la Corte Constitucional, tomo 96 , pp. 375, 394) y tienen que respetar la libertad decisoria del Parlamento como legislador. 


\section{OMISIÓN DEL LEGISLADOR}

Correspondiente a esto la Corte Constitucional se impone a sí misma una gran discreción en el enjuiciamiento de omisiones legislativas. Una omisión legislativa sólo puede ser calificada anticonstitucional cuando una obligación de actuar claramente determinada ha sido vulnerada de forma evidente. Esta limitación resulta del principio de la división de poderes y hay que considerarla también en nuestros casos explicativos - laserdromo, perros de pelea, pañuelo de cabeza. No obstante, en estos casos no se objeta una inactividad del legislador como tal, sino que se conecta indirectamente a la falta de una reglamentación explícita deseada del punto de vista de la Corte. El legislador no está constitucionalmente obligado a actuar, no obstante está de hecho coaccionado a promulgar una reglamentación correspondiente a la sentencia porque el tribunal ha prescindido de aplicar una norma en vigor ya existente.

Con ello se desacata la libertad que corresponde al legislador para enjuiciar la necesidad de una reglamentación y elaborar el contenido de ella. El principio de la división de poderes sólo permite el control judicial dentro de límites estrechos. Esto es reconocido en lo concerniente a la legislación positiva, pero también reclama validez para el caso negativo cuando el legislador se abstiene de tomar una decisión.

\section{OBSERVACIÓN FINAL}

Con las sentencias mencionadas la jurisprudencia ha abierto un camino preocupante que no sólo conduce a un mayor incremento de la criticada oleada de leyes, sino también a una intensificación de la influencia directora de la jurisprudencia, lo cual no es compatible con su papel constitucional sin argumentos adicionales. Es cierto que entre el cambio social y la ruptura inesperada sólo se denota una zona borrosa y sin duda existen casos en los cuales la novedad fundamental y la importancia para el interés público de un supuesto exige una reglamentación legal tan urgente que sin ella la sumisión de la jurisprudencia a la ley se pone en cuestión. Pero también aquí es en primer lugar recomendable buscar una solución con las herramientas metódicas ya probadas, incluyendo la evolución jurídica, antes de que se arrojen por la borda la soberanía y la autoridad del legislador, que sólo está sometido a la Constitución. 